https://doi.org/10.18485/imp.2017.ch.4

\title{
LA INFLUENCIA ESPAÑOLA EN LA VERSIÓN PORTUGUESA DE LA HISTORIA DE VESPASIANO. LOS TIEMPOS COMPUESTOS
}

\begin{abstract}
Varios investigadores han llamado la atención sobre los numerosos castellanismos léxicos que contiene la versión portuguesa de la historia medieval conocida como Historia del muy noble Vespasiano, que narra la destrucción de Jerusalén por el emperador romano, editada en Lisboa en 1496 por Valentino de Morávia. La presencia de dichos castellanismos léxicos demuestra que el texto portugués es una traducción del español. Basándonos en tal suposición, en este estudio nos proponemos examinar, mediante el análisis contrastivo de ejemplos recogidos del texto de la edición de Lisboa y del de la edición de Sevilla, prácticamente idénticos en cuanto a contenido, si dicha influencia puede observarse también a nivel de la gramática, especialmente en el campo de los tiempos verbales compuestos de los verbos transitivos.
\end{abstract}

Palabras clave: morfosintaxis histórica española, morfosintaxis histórica portuguesa, lingüística iberorrománica, tiempos compuestos, influencia española en el portugués

\section{Introducción. Objetivos, antecedentes y metodología}

El objetivo de este estudio es examinar la configuración y el uso de los tiempos compuestos de verbos transitivos en dos ediciones del texto narrativo conocido como Historia del muy noble Vespasiano, emperador de Roma o La destrucción de Jerusalén. Esta obra, basada en el Evangelium Nicodemi, que cuenta la destrucción de Jerusalén por el emperador Vespasiano presentando los hechos históricos como venganza de la muerte de Jesucristo fue muy popular y difundida en la Europa medieval. En la Península Ibérica debió de tener, según explica Machado (s.f.: 5 y 2010: 113) ${ }^{2}$, diferentes versiones manuscritas hasta que dio origen

1 tberta@hist.u-szeged.hu

2 En el caso de Machado (2010) los números hacen referencia a la localización en la versión digitalizada del estudio (Kindle Locatins), no a páginas. 
a por lo menos tres ediciones en el siglo XV; dos de ellas aparecieron en español (Toledo 1492 y Sevilla 1499) y una en portugués (Lisboa 1496) ${ }^{3}$. Debido a que la edición de Sevilla y la de Lisboa son idénticas en cuanto al contenido, surgieron diferentes teorías referentes a su origen; mientras que Pereira (1905) sugiere que la versión española de Sevilla procede de la portuguesa de Lisboa, Hook y Newman (1983: XIV) consideran más probable que hubo un manuscrito, ya perdido, escrito en español, que pudo servir de base para ambas versiones (Machado s.f.: 5). De todos modos, la presencia de numerosos castellanismos léxicos, mencionada por diversos filólogos, demuestra que la versión portuguesa de 1496 es una traducción del español (Machado s.f.: 5 y 2010: 126). Basándonos en tal suposición, en este estudio nos proponemos examinar, mediante el análisis contrastivo del texto de la edición de Lisboa y del de la edición de Sevilla, si la influencia de un original escrito en español puede observarse en la edición portuguesa también a nivel de la gramática, especialmente en la formación y uso de los tiempos verbales compuestos de los verbos transitivos. Ya hemos realizado un estudio similar utilizando ediciones distintas de esta misma obra narrativa con el objetivo de comparar el uso de los tiempos verbales compuestos en las dos lenguas peninsulares aquí mencionadas (Berta 2014a), pero sin la intención de indagar profundamente la cuestión del castellanismo morfosintáctico.

De hecho, el área de los tiempos compuestos se ofrece como un campo adecuado para examinar la influencia española en el texto portugués que nos interesa, debido a que las dos lenguas recorrieron básicamente el mismo itinerario histórico en el desarrollo de esta categoría gramatical nueva, pero a finales del siglo XV mostraban diferencias considerables en el comportamiento de los complejos verbales en cuestión.

Por una parte, en el período mencionado las dos lenguas diferían en la selección del verbo usado como auxiliar en los tiempos verbales compuestos. En la Edad Media ambas se caracterizan por la competición de los verbos procedentes de habere y tenere, ambos de significado de 'posesión' en su origen, en las construcciones que expresaban bien estado resultativo bien acción perfectiva o anterior -con frecuencia superior de haber+participio en el español (Pountain 1985: 343-344, Harre 1991: 113 y Olbertz

3 Acerca de las ediciones antiguas y modernas de la historia en las lenguas de la Península Ibérica véase Baranda (1991). 
1998: 315) y sin preferencia clara por uno de los dos verbos en el portugués (Costa 2010: 64)-, pero a partir del siglo XV las dos lenguas parecen seguir preferencias distintas en este campo. Aunque tener+participio también se documenta con la función de auxiliar de tiempos compuestos (Yllera 1980: 293-294, García de Diego 1970: 236 y Lapesa 2000: 784), el español estabiliza definitivamente el uso de haber con este valor. Los textos portugueses del siglo XV, en cambio, ya muestran un leve predominio de ter, (Harre 1991: 113, Cardoso y Pereira 2003: 175, Osório s.f.: 6-7 y 2013: 125), que en el siglo posterior llega a desterrar casi completamente haver tanto en la función de auxiliar de tiempos compuestos como en la de verbo de posesión (Carrasco González 2014: 78 y Mattos e Silva 2002a: 131-134).

Por otra parte, también distingue las dos lenguas en el siglo XV la situación de la difusión de la eliminación de la concordancia del participio con el complemento directo, considerada indicio de la desemantización del verbo de posesión y signo de la gramaticalización de la estructura. La desaparición de la concordancia tiene importancia teórica desde el punto de vista de la aparición de la categoría de los tiempos compuestos, puesto que, para una parte de los lingüistas "[e]nquanto [...] se verifica a concordância, não temos consolidada a formação dos tempos compostos" (Costa 2010: 65) -opinión compartida indirectamente por Dias (1959: 250; 326), Said Ali (1964: 160), Mattoso Câmara Jr. (1975: 166), citados por Mattos e Silva (2002a: 129), así como por Mendoça Cohen (1988: 48)-, mientras que para otros la concordancia es perfectamente compatible con la categoría del tiempo compuesto puesto que, según dicen Cardoso y Pereira (2003: 167) "parece não existir nenhum conflito entre a construção de tempo composto e o acordo participial". Por lo que se refiere a la cronología de la difusión de la sintaxis no concordante en las dos lenguas, se debe decir que para el siglo XV el español ya había consolidado las estructuras sin concordancia (Andres-Suárez 1994: 64, Calzado Roldán 1997: 23, García de Diego 1970: 234, Hanssen 1966: 230, Lapesa 2000: 783, Penny 2006: 193-194 y Romani 2006: 284), en el portugués, en cambio, la no-concordancia solo comenzó a difundirse a partir de la primera mitad del siglo XVI (Costa 2010: 65) y parece triunfar a mediados del mismo (Mattos e Silva 1997: 275, 2002a: 129-134 y 2002b: 152-155)4. Se

4 Es cierto que Carrasco González (2013: 175-178) observa el uso exclusivo de ter como auxiliar combinado con participio casi siempre concordado en obras de Bernardim Ribeiro, pero este parece ser un rasgo arcaizante del autor analizado. 
puede afirmar, por tanto, con Carrasco González (2015: 87) que "[h]ay, pues, un retraso considerable en portugués en el proceso de gramaticalización de los verbos auxiliares en la formación de los tiempos compuestos".

Finalmente, a finales del siglo XV las dos lenguas tenían tendencias distinas en cuanto a la frecuencia de formas verbales sintéticas y complejos verbales usados para expresar perfectividad y anterioridad. Mientras que el uso de formas compuestas era minoritario (Rodríguez Molina 2003: 292-294) u ocasional (Huber 2006: §415) de modo uniforme en todos los romances peninsulares antiguos, para el siglo XV se había creado una diferencia considerable entre las dos lenguas aquí analizadas en cuanto a la frecuencia de empleo de las alternantes simples y compuestas. En el español las formas de pluscuamperfecto simple del tipo cantara habían sido casi completamente sustituidas por las formas compuestas del tipo había cantado para principios del Siglo de Oro español (Lapesa 1988: 403 y Penny 2006: 234); a propósito del llamado mais-que-perfeito portugués, en cambio, Brocardo (2012: 35) constata la continuidad de numerosas ocurrencias de las formas simples en todo el período situado entre los siglos XIII y XVI. El uso de formas simples continúa hasta el estado actual del portugués, donde cantara alterna con tinha cantado o havia cantado (Cunha-Cintra 2000: 386-400 y 455). Vázquez Cuesta y Mendes da Luz (1987: 208) mencionan que "la lengua familiar de hoy da a las formas compuestas indiscutible predominio sobre las simples", pero el mantenimiento de las formas perfectivas sintéticas para estas mismas autoras es un rasgo conservador del portugués (Vázquez Cuesta y Mendes da Luz 1987: 60), que une este idioma con otros romances occidentales de la Península Ibérica (Andrés Díaz 2013: 600).

La problemática de la influencia española en la evolución de los tiempos verbales compuestos del portugués ya ha sido examinada en estudios previos. Boléo (1937) formula la hipótesis, citada y criticada por Irmen (1966), de la influencia del español en el desarrollo del perfeito composto portugués. Recientemente Carrasco González (2014 y 2015), analizando la frecuencia de la estructura haver+participio en obras de autores portugueses del período entre mediados del siglo XVI y mediados del siglo XVII, investiga la posible influencia española en la evolución de los tiempos verbales del portugués. Aplicando una metodología similar, 
nos hemos propuesto la idea de contrastar la versión española de Sevilla y la versión portuguesa de Lisboa de la Historia de Vespasiano para examinar si esta última muestra rasgos susceptibles de ser considerados castellanismos. Hemos partido de la hipótesis de que el empleo frecuente de haver como auxiliar, la alta proporción del participio no concordado o el porcentaje extrañamente alta de formas compuestas pueden ser considerados indicadores de la influencia del español en la morfosintaxis del texto portugués.

Para el análisis hemos utilizado la edición digital de Machado (2010), que, además de publicar una versión modernizada en portugués, una versión en francés y la española de Toledo, reproduce fielmente las ediciones de Sevilla y de Lisboa. El proceso de la recogida de datos siguió las siguientes fases: primero recogimos las estructuras transitivas construidas con haber o tener de la edición de Sevilla, después seleccionamos todas las oraciones que en la edición de Lisboa correspondían a las construcciones españolas ya registradas, independientemente de si contenían complejos verbales o formas verbales simples. De esta manera se creó una base de datos bilingüe constituida exclusivamente por estructuras paralelas, registradas en ambas ediciones. Como consecuencia de este método fueron excluidas las asimetrías causadas por lagunas en alguna de las versiones ${ }^{5}$.

A continuación se analizan los ejemplos paralelos contrastando los datos de las dos versiones arriba descritas y siguiendo la estructura siguiente. Primero se examina la proporción de los verbos procedentes de habere y tenere combinados con participios, después se analiza la frecuencia de los casos de concordancia y de no-concorancia del participio con el complemento directo y se contrastará el empleo de las formas verbales paralelas de acuerdo con el sistema de los tiempos verbales compuestos del español; a continuación se dedicará un apartado especial a algunos casos de interpretación ambigua, cuyo análisis es crucial para la cuestión aquí examinada; finalmente se esbozarán las conclusiones basadas en los datos recogidos.

5 El procedimiento aquí aplicado difiere, por tanto, del que utilizamos en Berta (2014a), que no evitó las asimetrías procedentes de las diferencias existentes entre las dos versiones utilizadas en aquel estudio. 


\section{El uso de los verbos ${ }^{6}$}

El primer parámetro que nos proponemos analizar es la alternancia de los verbos procedentes de habere y tenere, que en las construcciones transitivas formadas con participio, como hemos visto, en mayor o menor grado caracteriza ambas lenguas desde los textos medievales más antiguos. En nuestro corpus, se han registrado 101 ejemplos paralelos; entre ellos hay 39 en los que ambas ediciones utilizan complejos verbales, en el resto solo la de Sevilla. En esta misma edición hemos registrado tres construcciones que contienen el verbo tener, que se oponen a 98 estructuras formadas con el verbo auer. Los tres casos con tener forman paralelo con tres oraciones portuguesas que utilizan teer-véanse los ejemplos aducidos en (1) ${ }^{7}$-; de entre los restantes 36 ejemplos donde la edición de Sevilla usa el verbo auer, la de Lisboa coincide con aquella 11 veces por emplear el mismo verbo -como en el par de ejemplos aducido en (2)-, mientras que se muestra diferente en 25 casos aplicando el verbo teer -24 veces como en (3)- o bien recurriendo a una construcción pasivizada con seer -el único caso registrado de este tipo se ve en (4)-.

(1) a. Quãdo Pilatos supo que tan grãdes valles e tã ayna auia fecho el Emperador e tã estrecha mẽte los tenia apremiados allego su cõsejo (Sevilla, KL 5915-5917).

b. E quãdo Pilatus soube que tam grandes vallas e tã asinha avya feytas o emperador e tam estreitamẽte os tinha apertados. Chegou seu cõselho (Lisboa, KL 4172-4174).

c. aqueste castillo era de vn sabio judio e buẽ cauallero e sabia mucho de guerra e tenia el castillo biẽ bastescido de armas e de viandas (Sevilla, KL 5622-5625).

6 A continuación, al referirnos a los verbos en cuestión, seguimos la grafía de las ediciones analizadas. Utilizaremos, por tanto, las formas gráficas auer y tener en el español y aver y teer en el portugués.

$7 \quad$ Al citar los ejemplos, entre paréntesis nos referimos a la edición original de Sevilla y Lisboa, respectivamente, pero ofrecemos los datos de referencia de la versión digital del 2010 (KL=Kindle Locations). 
d. este castello era de huũ sabedor judeu e bom caualleyro e sabia muyto de guerra. E tinha o castello bem basteçido darmas e de viãdas (Lisboa, KL 3879-3881).

e. como Jafel vido que el ẽperador lo tenia assi cercado tan fuerte mẽte vino cõ tres caualleros al emperador (Sevilla, KL 5626-5627).

f. E como Jafel vio que o emperador o tinha assy çercado tam fortemẽte veo cõ tres caualleyros ao emperador (Lisboa, KL 3881-3883).

(2) a. E Sãt Clemeynte se partio del enperador cõ grãde gozo por quãto auia acabado su ẽtẽdimiẽto cõel ẽperador (Sevilla, KL 6550-6552).

b. Sam Clemẽte partiose do emperador cõ grãde prazer, porque auia acabado [o seu entendimento] cõ o emperador. (Lisboa, KL 4826-4829).

(3) a. Señores biẽ vedes vos que nos no podemos tener cõtra el emperador: ca dios nos a oluidado e nigũas viãdas no auemos ẽ aquesta cibdad (Sevilla, KL 6238-6240).

b. Senhores bem vedes vos que nos nõ nos podemos teer [contra] ao emperador que deus nos tẽ esqueeçido, e nẽhũas viãdas nõ teemos nesta çidade (Lisboa, KL 4493-4496).

(4) a. e quãdo ouo fecho el oficio dixo al pueblo ẽtrad dẽtro enel agua: (Sevilla, KL 6582-6583).

b. E des que foy feyto o officio disse ao pouoo: metevos dẽtro na augoa (Lisboa, KL 4860-4861).

Los verbos tener y teer, respectivamente, mantienen el significado de 'posesión' en todos los ejemplos aducidos en (1), lo cual implica que constituyen construcciones estáticas resultativas y no forman parte de tiempos compuestos. Aun aceptando la compatibilidad de la concordancia del participio con la categoría de los tiempos compuestos, en (1a-b) se ve claramente una oposición entre las construcciones los tenia apremia- 
dos y os tinha apertados y las estructuras tã ayna auia fecho y tã asinha avya feytas, respectivamente. En estas los adyacentes adverbiales tã ayna y tã asinha indican referencia a una acción perfectiva, apoyada en la versión española por la falta de concordancia del participio, mientras que en aquellas tanto la formas imperfectivas tenia y tinha como la consecuente concordancia de los participios apremiados y apertados con los complementos clíticos los y os, respectivamente, aclaran que se trata de un estado resultativo. También en (1c-f), pese a que los complementos directos masculinos en singular - el castillo, lo y o castello, o- no hacen transparente la concordancia del participio, el contexto descriptivo sugiere que se trata de estructuras estáticas resultativas. Estos ejemplos, por tanto, no se deben incluir en el análisis de los tiempos compuestos.

Volviendo a la cuestión de la proporción de los verbos rivales, observamos diferencias considerables entre las dos ediciones. En la de Sevilla tener apenas alcanza el 3\% frente al $97 \%$ de auer; además, como acabamos de ver, tener se limita a construcciones resultativas, lo que implica que los tiempos compuestos se construyen exclusivamente con auer. En nuestro corpus, por tanto, no se refleja el uso del verbo tener como auxiliar de tiempos compuestos mencionado por Yllera (1980: 293-294). En la edición de Lisboa, sin embargo, la frecuencia de aver se encuentra alrededor del $30 \%$, y la de teer está cerca del 70\%, proporción que es completamente compaginable con las cifras publicadas por Osório para el siglo XVI $-31 \%$ para aver y $69 \%$ para teer, respectivamente-, por tanto se puede decir que los datos estrictamente numéricos no muestran una proporción tan alta de aver en la edición portuguesa que sea explicable necesariamente por influencia española.

\section{La concordancia del participio}

El segundo parámetro que examinamos es la proporción de los casos de concordancia y no-concordancia del participio en las construcciones registradas. Fuera de las construcciones resultativas ilustradas en (1), donde la concordancia es obligatoria, el resto de los ejemplos muestra la alternancia de la sintaxis concordante y no concordante en ambas ediciones, como se puede observar en los ejemplos aducidos en (5-8). 
En (5a), (5c) y (5e) se presentan los tres ejemplos recogidos en la edición de Sevilla que presentan concordancia del participio con el complemento directo, destacado en negrita. En las construcciones portuguesas correspondientes -citadas en (5b), (5d) y (5f)- se utiliza una forma verbal simple, hecho que hace imposible que se contrasten las dos versiones, pero que confirma que estas construcciones españolas concordantes deben ser consideradas tiempos verbales compuestos.

(5) a. e miẽbra se te de todo esto que as visto e cree las palabras que el tu senescal te ha dichas (Sevilla, KL 5398-5399).

b. e lembrete de todo ysto que viste e cree as pallauras que o teu mestre salla te disse. (Lisboa, KL 3656-3658).

c. quãdo el enperador ouo leydas las cartas e supo que de tal guisa Pilatos era muerto fizo se mucho marauillado (Sevilla, KL 6785-6787).

d. E des que o emperador leeo as cartas e soube que de tal guisa Pilatus era morto fezese muyto marauilhado (Lisboa, KL 5072-5075).

e. e fizo muy grãdes gracias a dios como los auia alũbrados (Sevilla, KL 6579).

f. e deu grãdes graças a Deos que os alomiara (Lisboa, KL 4857-4858).

En (6-7) se presentan los cinco ejemplos de la edición de Lisboa en los que el participio -precedido por aver en (6) y por teer en (7)- muestra concordancia con el complemento directo destacado en negrita; como se puede apreciar, las oraciones españolas correspondientes contienen participios no concordados precedidos siempre por auer. Nótese que en (7g) la versión española usa un sustantivo masculino singular, mientras que en (7h) la oración portuguesa utiliza un sustantivo femenino, por tanto aquí la comparación no puede ser completa. De lo expuesto se deduce que la sintaxis concordante aparece en la edición portuguesa una sola vez cuando el auxiliar es aver, y cuatro veces con el auxiliar teer-cfr. (6) y (7)-. 
(6) a. Quãdo Pilatos supo que tan grãdes valles e tã ayna auia fecho el Emperador e tã estrecha mẽte los tenia apremiados allego su cõsejo (Sevilla, KL 5915-5917).

b. E quãdo Pilatus soube que tam grandes vallas e tã asinha avya feytas o emperador e tam estreitamẽte os tinha apertados. Chegou seu cõselho (Lisboa, KL 4172-4174).

(7) a. Señor pues dios vos a fecho tãta merced que sodes sano muy biẽ (Sevilla, KL 5560-5561).

b. Senhor pois deus vos tem feita tãta merçee que soees saão muy bem. (Lisboa, KL 3817-3818).

c. Bien me tẽgo por sañudo delas palabras que has dicho: e avn mas por quanto me mãdas tornar a Roma. (Sevilla, KL 5767-5769).

d. Tenho grãde menẽcoria das pallauras que teẽs ditas e ajnda mais porque me mãdas tornar. (Lisboa, KL 4021-4023).

e. Señor pues Jhesu Christo nuestro señor vos a fecho tãta de gracia que auedes tomado vẽgãça dela su muerte e sodes sano cõ toda la vuestra gẽte e ruego vos que le tẽgades lo que le pusistes (Sevilla, KL 6525-6532).

f. Senhor pois Jhesu Christo nosso senhor vos tẽ feita tãta graça que tomastes vingãça de sua morte: e soes saão cõ toda vossa gẽte, rogamos que lhe mãtenhas todo o que lhe prometestes (Lisboa, KL 4804-4810).

g. quiso que primero fablasse Jacob al qual dios auia fecho mucho bien aquel dia (Sevilla, KL 5890-5891).

h. e quis que primeyro fallasse Jacob ao qual deus tinha feyta muyta merçee aquelle dia (Lisboa, KL 4145-4146).

Los ejemplos aducidos en (8) y (9) contienen pares de estructuras en que el participio no está concordado con el complemento directo, destacado en negrita, en ninguna de las dos versiones. En las oraciones españolas, de acuerdo con las expectativas, el auxiliar es siempre auer, mientras que las oraciones portuguesas muestran la alternancia de aver y teer -cfr. (8) y (9)-. Nótese que en (9h) la presencia del pronombre masculino singular o impide la interpretación clara del enunciado. 
(8) a. e aquesta muger he traydo (Sevilla, KL 5362).

b. e esta molher vos ey trazido (Lisboa, KL 3560).

c. En aquella sazõ Gays su senescal fue llegado a Roma: el emperador auia fecho juntar sus cortes de todos los nobles de su jmperio (Sevilla, KL 5350-5351).

d. e em aquella razom Gays seu mestre salla chegou a Roma. O emperador avia ajuntado suas cortes de todos os nobres de seu emperio (Lisboa, KL 3540-3542).

e. e demando le que si auia hallado qualquier cosa con que el ouiesse salud: e sanasse de su enfermedad (Sevilla, KL 5355-5357).

f. e preguntou the se avya achado algũa cousa com que ouuesse saude e fosse saão de sua doença e enfermidade (Lisboa, KL 3550-3551).

(9) a. Señores biẽ vedes vos que nos no podemos tener cõtra el emperador: ca dios nos a oluidado e nigũas viãdas no auemos ẽ aquesta cibdad (Sevilla, KL 6238-6240).

b. Senhores bem vedes vos que nos nõ nos podemos teer [contra] ao emperador que deus nos tẽ esqueeçido, e nẽhũas viãdas nõ teemos nesta çidade (Lisboa, KL 4493-4496).

c. assi como ellos dieron al señor major por treynta dineros biẽ assi he dado treynta judios por vn dinero e estos judios que son quedados sean para mi e guardad los biẽ. (Sevilla, KL 6384-6386).

d. assi como elles derõ ao senhor mayor por xxx. dinheyros: bem assi tenho dado xxx. judeus por huũ dinheiro, e estes judeus que ficã sejã para my e guardayos bẽ, (Lisboa, KL 4657-4661).

e. e quãdo ouo rescebido los treynta dineros que se arrepintio dela trayciõ e del mal que avia fecho e que torno los dineros a los judios: (Sevilla, KL 5173-5175).

f. [e de] pois que tem reçebido os trinta dinheiros que se arrepẽdeo da treiçã e do mal que tijnha feito e que tornara os dinheiros aos judeus (Lisboa, KL 3311-3314). 
g. Y los senadores dixerõ todos ẽ vno que biẽ auiã entẽdido las sus palabras e erã aparejados de cõplir la su volũtad por derecho e por razõ. (Sevilla, KL 6686-6688).

h. E os senadores todos em huũ disserõ, que bẽ o tinhã entẽdido suas pallauras, e erã prestes para cõprir sua voõtade (Lisboa, KL 4967-4969).

Pese a que las dos ediciones coincidan en documentar la alternancia de la sintaxis concordante y no concordante del participio, se muestran muy diferentes en cuanto a la proporción de estas alternativas morfosintácticas. Sin tener en cuenta los tres pares de ejemplos obviamente resultativos citados en (1), se documentan tres casos de concordancia en la versión española y cinco en la portuguesa. Estas cifras absolutas no difieren demasiado, sin embargo se debe tener en cuenta que los tres ejemplos españoles constituyen el $3 \%$ de los 98 casos recogidos, mientras que los cinco casos de concordancia del portugués representan el $14 \%$ de las 35 construcciones que contienen haver o teer-eliminando el único ejemplo formado con seer, aducido en (4b)-. Las discrepancias entre las dos ediciones aumentan cuando examinamos la proporción de los casos sin concordancia participial respecto a la totalidad de ejemplos: en la de Sevilla se han registrado en total 38 casos sin concordar, mientras que en la de Lisboa se documentan siete ocurrencias de esta alternativa sintáctica, que representan el $38 \%$ y el $19 \%$ de la totalidad de ejemplos de construcciones susceptibles como tiempos compuestos. Además, descontando los ejemplos restantes, con complemento directo masculino singular, dudosos desde el punto de vista de la concordancia, y contrastando solo los casos transparentes de concordancia y no-concordancia, podemos observar que en la versión española se oponen tres ejemplos de concordancia a 38 de no-concordancia, mientras que en la portuguesa cinco ejemplos concordantes a siete no concordantes.

La proporción baja de los casos concordantes en la versión española está en consonancia con los datos ofrecidos por la bibliografía especializada arriba citada (Andres-Suárez 1994: 64, Lapesa 2000: 783, Yllera 1980: 284), que considera posible, pero esporádica dicha alternativa morfosintáctica en esta época; la predominancia ligera de la no-concordan- 
cia en la edición portugesa, en cambio, no corresponde a las expectativas puesto que según otros estudios en esta lengua tal innovación en el período examinado estaba muy limitada (Carrasco González 2015: 88-89, Berta 2014b: 233-234). La frecuencia relativamente alta de la falta de la concordancia en la edición de Lisboa, por tanto, puede ser atribuida a la influencia de un original escrito en español.

Frente a la edición de Sevilla, en la que la no-concordancia solo se documenta con auer, en la edición de Lisboa, donde aver y teer alternan en la función de auxiliar, resulta interesante examinar la distribución de la ausencia de la concordancia entre las construcciones formadas con un verbo u otro. Se puede constatar que cuando el auxiliar es aver, a un caso de concordancia participial se le oponen tres casos sin concordar, mientras que cuando se utiliza teer con esta función, ambas alternativas llegan a cuatro ocurrencias. Siguiendo la argumentación de Carrasco González (2014: 89; 2015: 89), que sostiene que en el portugués de la época los participios combinados sea con aver sea con teer debían de mostrar comportamiento semejante en cuanto la concordancia, hemos de suponer que la proporción más alta de la falta de concordancia en el caso de la estructura aver+participio también se debe a la influencia de un original español, donde esta construcción aparecería generalmente con el participio invariable.

\section{El uso de los tiempos verbales}

\subsection{Formas compuestas versus formas simples}

Así como se ha mencionado más arriba, una diferencia que separa la evolución morfosintáctica del sistema verbal del español y la del portugués consiste en que el primer idioma llegó a sustituir las formas sintéticas de anterioridad y perfectividad heredadas del latín con formas verbales compuestas, mientras que el segundo ha mantenido el uso de las formas sintéticas y hasta hoy utiliza los llamados tiempos verbales compuestos de una manera más restringida (Vázquez Cuesta-Mendes da Luz 1984: 60). En nuestro corpus se confirma la preferencia que el portugués tiene por las formas verbales sintéticas puesto que de los 101 pares de construcciones donde la edición de Sevilla usa complejos verbales, en 
62 la edición de Lisboa contiene formas verbales simples. A continuación contrastamos el empleo de formas verbales partiendo del sistema de tiempos compuestos documentado en la versión española; en la sección 4.2. trataremos de los pretéritos perfectivos que siguen el modelo de he cantado, mientras que en apartado 4.3. nos dedicaremos al análisis de auia cantado y oue cantado, que expresan anterioridad en el pasado.

\subsection{Formas equivalentes al tipo he cantado}

En el corpus bilingüe se han registrado en total 30 pares de estructuras donde la edición sevillana contiene construcciones de pretérito perfecto compuesto del tipo he cantado a las que en la lisboeta les corresponden soluciones variadas. De esta totalidad de ejemplos el texto portugués en 20 casos utiliza formas simples, mientras que en 10 ejemplos hace uso de formas compuestas, de estructura similar a las construcciones españolas.

De los 20 casos donde el redactor de la versión portuguesa usa formas simples, en 15 aparecen formas correspondientes al llamado perfeito simples, mientras que en dos el presente. Los ejemplos aducidos en (10) ilustran esta situación, donde las formas compuestas españolas ha embiado y as renegado se corresponden con las portugesas enuiou, mandou y arrenegaste, respectivamente. Es especialmente interesante el caso del ejemplo español aducido en $(10 \mathrm{~g})$, donde, de acuerdo con las posibilidades sintácticas ofrecidas por el estado lingüístico de la época, hecho y ordenado, como participios coordinados, dependen del mismo auxiliar $a$; según se ve en (10h), en la versión portuguesa se sigue esta misma estructura de coordinación, pero incluye dos formas verbales de perfecto simple, fez y ordenou.

(10) a. e dezid a Pilatos mi adelantado que como no me ha embiado el tributo que me deue de siete años e dalde esta carta mia. (Sevilla, KL 5208-5209).

b. E dizee a Pilatos meu adiãtado que como me nõ enuiou o trebuto que me deue de sete ãnos e daylhe esta carta minha. (Lisboa, KL 3364-3366).

c. dios me ha ẽbiado a vosotras (Sevilla, KL 6111). 
d. Deos me mãdou a vos outras (Lisboa, KL 4380).

e. Jacob cõdenado eres a muerte por quãto has renegado la nuestra ley (Sevilla, KL 5840-5841).

f. Jacob condẽpnado es a morte por quanto arrenegaste a nossa ley (Lisboa, KL 4102).

g. mas creo que dios lo a fecho e hordenado por quãto el non la ovo de aquel que era saluador de todo el mũdo (Sevilla, KL 2563-2564).

h. mas creo que deus o fez e ordenou por quãto elle ha nõ ouue da quelle que era saluador de todo o mũdo. (Lisboa, KL 4035-4038).

En dos casos, que se presentan en (11), la versión portuguesa usa formas de presente donde la española emplea el perfecto compuesto: se puede observar que las construcciones españolas no se han podido hallar y vos he aqui traydo forman paralelo con las portuguesas nõ se podẽ achar y vos aqui trago, respectivamente.

(11) a. por que vos deuedes de saber que mi señor el emperador ha vna dolẽcia muy fuerte en la su faz e no se han podido hallar fisicos ni çurujanos enel mũdo que lo puedã guarescer (Sevilla, KL 5234-5237).

b. porque vos deuees de saber que meu senhor o emperador tẽ hũa doença forte e fea em seu rostro e nõ se podẽ achar fisicos nem çelorgiãos no mũdo que o possã dar saão (Lisboa, KL 3403-3407).

c. seredes luego sano: e limpio dela vuestra enfermedad bien assi como aquella muger que vos he aqui traydo (Sevilla, KL 5368-5369).

d. serees logo saão e limpo de vossa ẽfermidade. Bẽ asy como esta molher que vos aqui trago (Lisboa, KL 3566-3568).

En los tres tres casos restantes la forma perfectiva compuesta española aparece en el modo subjuntivo, debido a que se refiere a un acontecimiento 
futuro anterior a otro expresado en una proposición subordinada adverbial de tiempo; la versión portuguesa en estos casos utiliza formas simples o bien de presente do conjuntivo o bien de futuro do conjuntivo. De este modo, en (12a-b) a la construcción española aya vẽgado le corresponde la forma portuguesa vingue mientras que en (12c-d) y (12e-f) a aya tomado la forma de presente tome y la forma de futuro tomar, respectivamente.

(12) a. Mas sabed que yo no me bautizare fasta que yo aya vẽgado la muerte de Jesu Christo (Sevilla, KL 5538-5540).

b. mas vos sabee que eu me nõ bautizarey ate que eu nõ vingue a morte de Jesu Christo. (Lisboa, KL 3795-3798).

c. prometo vos que luego que sea venido de Jerusalẽ si a dios plaze e aya tomado vẽgãça delos crueles judios que yo me bautizare cõ todo el mi pueblo. (Sevilla, KL 5540-5545).

d. E prometo vos que logo tãto que eu vier de Jherusalẽ se a deus apraz que eu tome vingãça dos cruees judeus eu logo me bautizarey cõ todo o meu pouoo: (Lisboa, KL 3791-3801).

e. E como aya tomado vengãça en Jerusalẽ: e sere tornado ẽ Roma sy a dios plaze yo me fare baptizar: (Sevilla, KL 5407).

f. E como tomar vingãça em Jherusalem me tornarey a Roma se a deus aprouuer eu me farey bautizar (Lisboa, KL 3667-3670).

En la edición de Lisboa se documenta diez veces el uso de estructuras compuestas que corresponden al perfecto compuesto español. En estas diez ocurrencias predomina el uso de teer como auxiliar, pero también se han registrado dos casos con aver. El uso predominante de teer se ilustra con los ejemplos que se presentan en (13), donde las formas españolas a fecho, has dicho, fecho auemos y a oluidado son paralelas a las portuguesas tem feita, teẽs ditas, feito teemos y tẽ esqueeçido, respectivamente. En (14) se presentan las dos estructuras donde ambas ediciones usan el auxiliar auer o aver: aquí las construcciones españolas he traydo y vos a sanado son totalmente paralelas a las portuguesas ey trazido y vos ha saarado, respectivamente. 
(13) a. Señor pues dios vos a fecho tãta merced que sodes sano muy biẽ (Sevilla, KL 5560-5561).

b. Senhor pois deus vos tem feita tãta merçee que soees saão muy bem. (Lisboa, KL 3817-3818).

c. Bien me tẽgo por sañudo delas palabras que has dicho: eavn mas por quanto me mãdas tornar a Roma. (Sevilla, KL 5767-5769).

d. Tenho grãde menẽcoria das pallauras que teẽs ditas e ajnda mais porque me mãdas tornar. (Lisboa, KL 4021-4023).

e. Señor fecho auemos tu mãdamiẽto: e mãda lo que fagamos. (Sevilla, KL 6255-6256).

f. Senhor feito teemos teu mandado manda o que façamos. (Lisboa, KL 4515-4516).

g. Señores biẽ vedes vos que nos no podemos tener cõtra el emperador: ca dios nos a oluidado (Sevilla, KL 6238-6240).

h. Senhores bem vedes vos que nos nõ nos podemos teer [contra] ao emperador que deus nos tẽ esqueeçido, (Lisboa, KL 4493-4495).

(14) a. e aquesta muger he traydo (Sevilla, KL 5362).

b. e esta molher vos ey trazido (Lisboa, KL 3560).

c. Señor pues que dios vos a dado salud e tãta misericordia que vos a sanado de tã fuerte ẽfermedad que os plega que por el su amor que vos bautizedes (Sevilla, KL 5500-5504).

d. Senhor pois que deus vos deu saude e tanta misericordia ouue com vosco que vos ha saarado de tam forte enfermidade praza vos que por o seu amor vos bautizees (Lisboa, KL 3760-3763).

También se ha registrado un caso donde a la forma española de pretérito perfecto compuesto, que-de modo similar a los casos aducidos en (12) - aparece en el modo subjuntivo y se refiere a una acción del futuro, le corresponde una contrucción portuguesa igualmente compuesta, formada por el infinitivo de teer y el participio. Se trata del par de oraciones aducido en (15), donde el español aya cõplido forma paralelo con el portugués teer cõprido. 
(15) a. Ca por cierto yo no sere alegre fasta auer tomado vengança e aya cõplido todo lo que prometi a nuestro señor (KL 5545-5546).

b. que por çerto eu nõ serey alegre nẽ contẽte atee eu tomar vingança e teer cõprido todo o que prometi a nosso senhor (Lisboa, KL 3801-3803).

\subsection{Formas perfectivas de anterioridad en el pasado}

\subsubsection{Formas equivalentes al tipo auia cantado}

En nuestro corpus bilingüe hemos registrado en total 25 ejemplos paralelos en los que la versión española usa la construcción del tipo auia cantado y la portuguesa utiliza formas verbales simples. En la mayoría de los casos se trata de contextos de anterioridad en el pasado, que el portugués expresa con mais-que-perfeito simples en el modo indicativo -como en (16a-f), donde a las formas compuestas españolas auian visto, avia alũbrado y avia cõprado les corresponden las formas simples portuguesas viram, alomiara y comprara, respectivamente- o en el modo subjuntivo -como en (16g-h), donde el español ouiesse ouydo es paralelo al portugués ouuisse-. También se documenta cuatro veces el uso de las formas correspondientes al pluscuamperfecto -compuestos en el texto español y simples en el portugués- en la apódosis o en la prótasis de oraciones potenciales -como en (16i-j), donde oviera avido y ouiera demãdado se contrastan con ounera y pidira-.

(16) a. e ellos cõtaron le todo lo que auian visto ẽla casa dela Reyna de Africa. (Sevilla, KL 6148-6149).

b. E eles contaram-Ihe tudo que viram em casa da rainha de África. (Lisboa, KL 970).

c. e fizo muy grãdes gracias a dios como los auia alũbrados (Sevilla, KL 6579).

d. e deu grãdes graças a Deos que os alomiara. (Lisboa, KL 4857-4858). 
e. e vino ay el cauallero que avia cõprado el primer dinero de los judios ãtel ẽperador (Sevilla, KL 2878).

f. E veio aí o cavaleiro que comprara o primeiro dinheiro dos Judeus (Lisboa, KL 1085).

g. Despues que el emperador ouo dado licẽcia a los sus caualleros e se partierõ: el emperador mãdo al senescal que truxiese Pilatos delãte del e quãdo ouiese oydo la missa ãtes que comiese (Sevilla, KL 6637-6642).

h. Depois que o emperador deu liçẽça aos seus caualleiros e se partirõ, elle mãdou ao mestresalla que trouuesse Pilatus ante elle des que ounisse missa antes que comesse (Lisboa, KL 4916-4921).

i. Ca dios le oviera avido merced si gela ouiera demãdado e le perdonara. (Sevilla, KL 6797-6798).

j. que deus ouuera piedade cõ elle se Iha pidira (Lisboa, KL 5087-5088).

Es interesante, sin embargo, que en la versión portuguesa también se documenta el empleo del pretérito perfeito simples y del pretérito imperfeito con valor correspondiente al del pluscuamperfecto español; así, en (17) los plucuamperfectos compuestos españoles auia visto, auian hecho y auia sentido son sustituidos por viu, faziã y via, en los ejemplos portugueses. Cabe señalar que la primera solución es mencionada también por Huber (2006: §407), pero la segunda debe ser excepcional y quizás indique la mera intención de evitar la imitación de un original español que contenía formas compuestas.

(17) a. quando el Emperador desperto fue mucho marauillado desto que auia visto: e dixo en su coraçõ (Sevilla, KL 5401-5402).

b. E quando o imperador acordou, foi muito maravilhado do que viu, e disse em seu coração: (Lisboa, KL 624).

c. asi que muchas gẽtes se cõvertierõ ẽ aquellos ocho dias que nõ avia fecho de ãtes. (Sevilla, KL 2968-2970). 
d. E muytas gẽtes se cõuerterõ naquelles oyto dias o que nõ faziã dantes (Lisboa, KL 4797-4798).

e. dixo que nunca auia sentido tan buen holor de carne asada e (Sevilla, KL 6128-6129).

f. e disse que nũca via tã boõ cheiro da carne assada. (Lisboa, KL 4402-4403).

Por otra parte, también abundan los ejemplos que ilustran el uso paralelo de formas verbales compuestas que tienen valor de anterioridad en el pasado en ambas versiones del texto; se han recogido en total 21 pares de construcciones de este tipo. En 14 ejemplos de formas compuestas con valor de pluscuamperfecto, el texto portugués usa el verbo teer como auxiliar; algunos de estos casos se presentan en (18).

(18) a. pero que ya era mucho cõ grãde saña contra Jacob por las palabras que auia dicho. (Sevilla, KL 5835-5836).

b. ajnda que ja tinha grãde sanha cõtra Jacob pollas pallauras que lhe tinha ditas, (Lisboa, KL 4095-4097).

c. e fizo le gracias e merçedes del seruicio que fecho le avia (Sevilla, KL 5332-5333).

d. e deu lhe graças e merçees do seruiço que the tinha feito: (Lisboa, KL 3520-3521).

e. e lo pusierõ enel sancto sepulcro que Joseb auia fecho para si (Sevilla, KL 5470-5471).

f. e o poserõ em huũ moymento que Josep tijnha feyta para sy e resurgio ao terçeiro dia. (Lisboa, KL 3433-3435).

Los restantes siete casos muestran un uso totalmente paralelo de construcciones, debido a que en ambas versiones se utiliza el auxiliar aver. Estas ocurrencias de aver se presentan en los ejemplos aducidos en (19). Nótese que el par de oraciones aducido en (19f-g) representa el único caso donde el modo verbal de las construcciones es el subjuntivo; también aquí se observa un paralelo total entre las formas ouiese tocado y ounesse tocado. 
(19) a. e salio se diziẽdo que mal cõsejo auia tomado Pilatos. (Sevilla, KL 5328-5329).

b. e saiose dizẽdo, que mao cõselho auia tomado Pilato. (Lisboa, KL 3517-3518).

c. cuydauan que dios lo auia fecho por amor dellos (SeviIla, KL 6450-6452).

c. cuidauã que deus o auia feito por amor delles. (Lisboa, KL 4731-4733).

d. En aquella sazõ Gays su senescal fue llegado a Roma: el emperador auia fecho juntar sus cortes de todos los nobles de su jmperio (Sevilla, KL 5350-5351).

e. e em aquella razom Gays seu mestre salla chegou a Roma. O emperador avia ajuntado suas cortes de todos os nobres de seu emperio (Lisboa, KL 3540-3542).

f. si por ventura pudiessen auer algunas cosas: o reliquias que ouiessen estado de aquel sancto profeta o que o ouiese tocado (Sevilla, KL 5191-5193).

g. se polla vẽtura podessẽ auer algũas cousas ou reliquias que hy esteuessẽ daquele sãto profeta ou que o ounesse tocado (Lisboa, KL 3338-3342).

\subsubsection{Formas equivalentes al tipo oue cantado}

Lo que hace interesante esta forma, conocida como pretérito anterior en la terminología gramatical del español, es que, de modo similar al pluscuamperfecto del tipo auia cantado, envuelve la idea de anterioridad en el pasado, pero, también puede usarse con valor de pasado simple (Hanssen 1966: 234). Los diversos valores de pasado que coaparecen en la forma en cuestión tienen como consecuencia que esta puede ser sustituida en el español actual tanto con el perfecto simple como por el pluscuamperfecto. También se documenta en los textos portugueses medievales, pero Huber (2006: §416) solo lo menciona con aver y seer, no con teer, probablemente porque cayó en desuso paralelamente al avance progresivo de este verbo usado como auxiliar. 
En nuestro corpus se han registrado en total 17 pares de oraciones paralelas en las que una acción perfectiva, anterior a otra realizada en el pasado, en la versión española es expresada por construcciones formadas con el pretérito perfecto del verbo auer, mientras que en la versión portuguesa por formas verbales simples. De estos 17 casos, en 16 el verbo portugués aparece en perfeito simples. Eso es lo que ocurre en la selección de ejemplos presentada en (20), donde las construcciones y formas verbales destacadas en cursiva se encuentran en proposiciones subordinadas que expresan anterioridad respecto a la acción designada por el verbo de la proposición principal.

Merece la pena dedicar algunas palabras a las conjunciones que encabezan las proposiciones subordinadas de anterioridad. Los ejemplos aducidos en (20) muestran un uso paralelo de las mismas conjunciones subordinantes en ambas versiones: en (20a-d) se usa la conjunción quando -o su variante gráfica quãdo-, mientras que en (20e-f) la conjunción es como; estas preceden las formas compuestas ouo entẽdido, ouo acabado y ouo adorado en el texto español y las formas simples entendeu, acabou y adorou en el portugués. Dado que dichas conjunciones pueden introducir subordinaciones tanto de anterioridad como de simultaneidad, en las oraciones españolas aducidas es precisamente la forma compuesta de los verbos la que expresa la idea de anterioridad. En las oraciones portuguesas correspondientes, sin embargo, por falta de expresión estructural explícita la relación de anterioridad entre los verbos subordinados y los principales solo se deduce del contexto.

(20) a. E quãdo Pilatos ouo entẽdido al senescal rescibio la carta e fizo le mal rrostro (Sevilla, KL 5309-5310)

b. E quando Pilatos entendeu o mestre-sala, recebeu a carta e fez-Ihe mau rostro (Lisboa, KL 547-548).

c. e quando ouo acabado su sermõ dixo al ẽperador: (SeviIla, KL 5499-5500).

d. e quãdo acabou seu sermom disse ao emperador (Lisboa, KL 3759-3760).

e. E como el emperador ouo adorado el sãcto paño ẽ virtud del sancto profeta Sãt Clemyente lo puso ẽla cara del emperador. (Sevilla, KL 5486-5488). 
f. Christo. E como o emperador adorou o sancto panno em virtude de sancto profeta, Sam Clemẽte o pos no rostro do emperador, (Lisboa, KL 3744-3748).

En otros casos, sin embargo, en la versión portuguesa tal relación temporal existente entre las dos proposiciones se aclara gracias al uso de conjunciones de subordinación específicas. Eso es lo que se puede apreciar en los ejemplos aducidos en (21): en las estructuras portuguesas de (21b) y (21d) las conjunciones temporales dês que y tanto que se encargan de expresar la anterioridad, mientras que en las oraciones de la edición sevillana se usa consecuentemente la conjunción quãdo seguida de formas verbales compuestas. El uso de estrategias diferentes para explicitar la anterioridad puede ser el factor responsable de las frecuentes divergencias en la utilización de conjunciones temporales que menciona Machado (2008: 102-104) en su artículo dedicado al análisis comparativo de conectores y marcadores discursivos en la versión portuguesa y dos versiones españolas.

(21) a. e quãdo ouo acabado su sermõ e el oficio fue acabado e la missa fue dicho el emperador mãdo que todos los tẽplos delos ydolos fuesen derrocados (Sevilla, KL 66006603).

b. E des que acabou a preegaçõ e o officio foy acabado e a missa foy dita o emperador mãdou que todos os tẽplos dos ydollos e dos diaboos fossem destroydos (Lisboa, KL 4879-4882).

c. e quãdo el angel ouo metido a Jacob dentro ẽla tienda del Emperador desaparesciole. (Sevilla, KL 5872-5873).

d. E tãto que o anjo meteo Jacob na tẽda do emperador, dessapareçeo Ihe. (Lisboa, KL 4127-4129).

En un caso -citado en (22)- la idea de la anterioridad-expresada por la forma compuesta ouo acabado, de pretérito anterior- en la versión portuguesa se manifiesta mediante el uso de un gerundio -em acabando-. 
(22) a. e quãdo Sã Cle[m]yẽte ouo acabado el sermon vinierõ se Veronica e el delãte del emperador: (Sevilla, KL 5481-5482).

b. E em acabando Sam Clemente o sermõ vieronse Veronica e elle diante do emperador: (Lisboa, KL 3740-3741).

Pese a que en la versión portuguesa se pueda observar una clara preferencia por el uso de formas simples donde en la edición de Sevilla aparecen formas compuestas de pretérito anterior, también en la edición de Lisboa se documenta, aunque escasamente, el uso de formas compuestas con este valor. Hemos registrado en total cinco ejemplos en los que las dos ediciones son paralelas en el uso de construcciones verbales de este tipo, que reproducimos en (23).

(23) a. e quando lo ouieron cortado pusieron lo assar (Sevilla, KL 6126).

b. e quando o uirõ cortado poserõno a assar. (Lisboa, KL 4396-4397).

c. E quando o houveram cortado, puseram-no a assar. (Machado 2010, KL 958-959).

d. Despues quel emperador ouo elegido apostolico e cabeça dela cristiãdad fizo le edificar vna yglesia a hõrra e seruicio de dios (Sevilla, KL 5552-5553).

e. Despois que o emperador ouve emlegido apostolico e cabeça da christindade fezlhe e edeficar hũa ygreja a honrra e seruiço de deus. (Lisboa, KL 3807-3811).

f. e quãdo ouo rescebido los treynta dineros que se arrepintio dela trayciõ e del mal que avia fecho e que torno los dineros a los judios: (Sevilla, KL 5173-5175).

g. [e de] pois que tem reçebido os trinta dinheiros que se arrepẽdeo da treiçã e do mal que tijnha feito e que tornara os dinheiros aos judeus (Lisboa, KL 3311-3314).

h. E quãdo los ouo rescebido lleuo los a su tiẽda (Sevilla, KL 6334).

i. e des que os tenia reçebidos leuouos aa sua tenda. (Lisboa, KL 4602-4603). 
j. e quãdo ouo fecho el oficio dixo al pueblo ẽtrad dẽtro enel agua: (Sevilla, KL 6582-6583).

k. E des que foy feyto o officio disse ao pouoo: metevos dẽtro na augoa (Lisboa, KL 4860-4861).

En todas las oraciones arriba aducidas se verifica, pues, el uso de construcciones verbales para designar acciones producidas en el pasado con anterioridad a otras, que aparecen en proposiciones subordinadas de tiempo. Sin embargo, solo las construcciones portuguesas o uirõ cortado y ouve emlegido, en (23b) y (23e), muestran paralelo total con las españolas ouieron cortado y ouo elegido, presentadas en (23a) y (23d), en cuanto a las formas de auxiliar. En los demás casos el texto escrito en portugués ofrece soluciones bastante variadas para indicar la anterioridad: tanto tem reçebido como tenia reçebidos corresponden a ouo rescebido, mientras que la construcción transitiva española ouo fecho aparece en la versión portuguesa en forma pasivizada como foy feyto. Esta alternancia de formas variadas puede indicar que redactor-traductor del texto portugués vacilaba entre diversas soluciones ante la necesidad de representar la anterioridad inmediata expresada por una forma española compuesta -ouo+participio- que debía de parecerle extraña o anticuada.

El uso de la forma tem reçebido en el ejemplo aducido en (23g) llama la atención especialmente porque aparece en una proposición subordinada adverbial de tiempo introducida por el conector depois que, el cual destaca la idea de anterioridad en una oración situada en el pasado; este contexto es ajeno, en principio, al perfeito simples portugués. Desde el punto de vista contextual y sintáctico, pues, no se presenta ningún factor que justifique el uso de dicha forma verbal en esta oración compuesta, parece tratarse de una solución ad hoc para expresar anterioridad inmediata en el pasado.

Es especial el caso del par de ejemplos aducido en (23h-i). Por una parte, así como menciona Machado (2010: 243-244), es evidente que la forma tenia, documentada en la versión portuguesa, sea un castellanismo léxico que no encaja en el sistema morfosintáctico de esta lengua de nin-

$8 \quad$ Nótese que (23b) debe ser interpretada como (23c). 
gún modo. Por otra parte, desde el punto de vista estructural, no parece haber influencia española en la construcción portuguesa puesto que los ouo rescebido y os tenia reçebidos no forman paralelo: la versión portuguesa se distancia de la española en la elección del auxiliar teer y no aver, en el tiempo verbal del auxiliar y en la concordancia del participio con el complemento directo. Estas características convierten dicha proposición subordinada portuguesa en una estructura ambigua, que puede expresar tanto anterioridad inmediata -aproximadamente: 'cuando los hubo recibido' - como simultaneidad -aproximadamente: 'cuando ya los tenía (recibidos)' -. Tal ambigüedad no surge en el caso de la construcción española, que tiene un claro valor de anterioridad inmediata.

En el par de oraciones aducido en (23j-k) las dos versiones optan por soluciones completamente sinónimas, pero diferentes en la estructura superficial: la construcción transitiva activa del español y la pasiva del portugués muestran otra vez cierto distanciamiento en la elección de soluciones alternativas.

En resumen, llama la atención la gran variación de las soluciones equivalentes al pretérito anterior ofrecida por la versión portuguesa, que puede deberse, como hemos mencionado, al hecho de que en el portugués de finales del siglo XV no sería habitual el empleo de este tiempo verbal. Nótese que en esta época teer es el verbo predominante en los tiempos compuestos y la estructura del tipo teve cantado no se documenta en el corpus. De esta argumentación se deduce que los dos ejemplos portugueses documentados en (23b) y (23d) -o uirõ cortado y ouue emlegidose deben, probablemente, a la influencia de un original en español.

\section{Casos de alternancia dudosos}

El análisis expuesto demuestra que la versión portuguesa ofrece una gran variabilidad de alternativas respecto a la española tanto en la selección de auxiliares, como en la concordancia del participio y en el uso de estructuras compuestas o formas verbales simples. Esta gran variedad de alternativas se debe, en muchos casos, a la alternancia libre de estructuras lingüísticas formalmente diferentes pero funcionalmente equivalen- 
tes. Así, por ejemplo, al considerar los dos pares de oraciones aducidos en (24) y (25), se puede ver que a la forma compuesta española auia visto de (24a) y de (25a) en la edición portuguesa le corresponden la forma simple vio y la forma compuesta tijnha visto -en (24b) y (25b), respectivamente-.

(24) a. quando el Emperador desperto fue mucho marauillado desto que auia visto: e dixo en su coraçõ (Sevilla, KL 5401-5402).

b. E quãdo o emperador acordou foy mujto marauilhado do que vio, e disse em seu coraçõ (Lisboa, KL 3659-3661).

(25) a. E el emperador marauillo se mucho delo que auia visto (Sevilla, KL 5393-5394).

b. E o emperador marauilhouse muyto do que tijnha visto (Lisboa, KL 3654).

De modo similar, en el el ejemplo portugués del par aducido en (26) se observa la copresencia de varias formas verbales de pretérito de configuración heterogénea, equivalentes al pretérito perfecto compuesto del español. En la versión española tenemos una acción designada por la estructura a dado salud e tãta misericordia, que cuenta con dos complementos directos coordinados, y otra expresada por vos a sanado; en ambos casos se utiliza una forma verbal perfectiva compuesta. En la versión portuguesa se mantiene la estructura con dos complementos, pero estos se vinculan con dos formas verbales perfectivas simples en las estructuras deu saude y tanta misercordia ouue, mostrando así cierta divergencia frente al texto español; en cambio, la forma compuesta ha saarado es idéntica a la española. La variación de las formas simples deu, ouve con la compuesta ha saarado no parece responder a ninguna distribución funcional basada en diferencias aspectuales o temporales, debido a que en los tres casos se trata de una acción perfectiva del pasado que tiene consecuencias en el presente, por tanto también debe ser atribuida a alternancia libre. Aquí, sin embargo, no se puede excluir que la elección del verbo aver haya sido motivada por un original en español. 
(26) a. Señor pues que dios vos a dado salud e tãta misericordia que vos a sanado de tã fuerte ẽfermedad que os plega que por el su amor que vos bautizedes (Sevilla, KL 5500-5504).

b. Senhor pois que deus vos deu saude e tanta misericordia ouue com vosco que vos ha saarado de tam forte enfermidade praza vos que por o seu amor vos bautizees (Lisboa, KL 3760-3763).

En otros casos, en cambio, se observa una situación diferente a la que acabamos de describir, puesto que la alternancia de dos soluciones distintas ofrecida por la versión portuguesa no parece ser manifestación de una mera variación estilística.

Así, en el par de ejemplos aducido en (27) la versión española contiene aparentemente dos tiempos compuestos - as me negado y nõ me as ẽbiado-a los que en la portuguesa les corresponden una construcción compuesta y una forma de perfecto simple-me tens negado y não me enviaste, respectivamente-, posiblemente equivalentes, en alternancia libre. Sin embargo, la presencia del adverbio agora hace posible -incluso probableuna interpretación en la cual la construcción agora me teẽs negado o senhorio tiene valor resultativo y la forma simple ẽuiaste alude a una acción perfectiva producida en el pasado con efecto en el presente, según la interpretación que se propone en (27c). Nótese que esta interpretación, en realidad, también es viable en la versión española, puesto que el verbo medieval auer aún mantiene el valor de posesión también en esta época.

(27) a. e agora as me negado el señorio e no me as ẽbiado el tributo (Sevilla, KL 5723).

b. E agora me teẽs negado o senhorio, e nõ me ẽuiaste o trebuto. (Lisboa, KL 3975).

c. 'y ahora me tienes negado el señorío y no me has enviado el tributo'

Es similar el caso del par de construcciones aducido en (28), donde la versión española contiene dos formas verbales compuestas - $a$ fecho y auedes tomado-, mientras que la portuguesa una compuesta y una sim- 
ple -tẽ feita y tomastes, respectivamente-. Como en las construcciones españolas a fecho tãta de gracia y auedes tomado vẽgãça el participio no está concordado con el complemento directo, tales estructuras solo pueden ser interpretadas como tiempos verbales compuestos perfectivos. Por lo que se refiere a las construcciones portuguesas tẽ feita tãta graça y tomastes vingãça, solo en el caso de la segunda, con forma verbal simple, es evidente la función de pretérito perfectivo. En la primera, la forma concordada del participio hace posible que la estructura tẽ feita tãta graça pueda ser interpretable como resultativa en el presente, con el significado aproximado de 'tiene tanta gracia hecha'. Si esta argumentación es válida, podemos concluir, por una parte, que la frase española y la portuguesa aquí presentadas no muestran paralelismo total y, por otra, que las dos formas verbales portuguesas no son variantes estilísticas del pretérito perfectivo, sino que expresan contenidos distintos.

(28) a. Señor pues Jhesu Christo nuestro señor vos a fecho tãta de gracia que auedes tomado vẽgãça dela su muerte e sodes sano cõ toda la vuestra gẽte e ruego vos que le tẽgades lo que le pusistes (Sevilla, KL 6525-6532).

b. Senhor pois Jhesu Christo nosso senhor vos tẽ feita tãta graça que tomastes vingãça de sua morte: e soes saão cõ toda vossa gẽte, rogamos que lhe mãtenhas todo o que Ihe prometestes (Lisboa, KL 4804-4810).

A propósito de la alternancia de las formas simples y compuestas del mais-que-perfeito portugués, consideramos que es aceptable la hipótesis mencionada por Brocardo (2010: 124) que supone que no se trataría de variación completamente libre, sino que las últimas podrían tener valor resultativo. Esta aproximación parece ser justificada por algunos ejemplos registrados en nuestro corpus que se caracterizan aparentemente por la coaparición de formas simples y compuestas del mais-queperfeito. Así, en los ejemplos aducidos en (29) el texto español contiene las formas de anterioridad compuestas auia cõprado y auia asegurado, que dependen de las proposiciones principales de los verbos de pretérito vino y traxo, mientras que en el portugués a veo y trouxe se subordinan 
la forma simple cõprara y la compuesta tinha segurado, respectivamente. Estas últimas pueden funcionar, en principio, como dos soluciones equivalentes de pretérito perfectivo de anterioridad -es decir, de mais-queperfeito-en variación libre, pero también es posible que tinha y segurado formen parte de una construcción estática resultativa, expresando simultaneidad con veo y trouxe, y que la interpretación de la oración sea formulable como la que se ofrece en (29c).

(29) a. e vino ay el cauallero que auia cõprado el primer dinero de los judios ãte el emperador e traxo cõsigo el judio que el auia asegurado de muerte e dixo al ẽperador (Sevilla, KL 6417-6421).

b. e veo hi o caualleyro que cõprara o primeiro dinheyro dos judeus e veo diãte do emperador e trouxe cõ sigo o judeu que tinha segurado da morte, e disse ao emperador: (Lisboa, KL 4696-4700).

c. y vino allí el caballero que había comprado el primer dinero de los judíos ante el emperador y trajo consigo el judío que él tenía asegurado de muerte y dijo al emperador.

Es similar la situación en los ejemplos que se presentan en (30). En ambas versiones aparecen cinco formas verbales de pretérito, de las cuales cuatro están situadas en subordinaciones que jerárquicamente dependen de la primera -saco y tirou, respectivamente-. En la versión española las formas compuestas auiã metido, auia descẽdido, auia metido y auia fecho -entre las cuales existe una compleja relación temporal de anterioridad, todas expresan acciones del pasado anteriores a la que designa la forma perfectiva simple saco. En la versión portuguesa a las formas compuestas españolas les corresponden dos formas simples -deçera y metera- y dos compuestas -tinhã metido y tinha feito-. Aquí las relaciones temporales pueden ser idénticas a las que presenta la española, y puede tratarse de una alternancia libre entre formas verbales simples y compuestas de perfectividad y anterioridad, pero también es posible que las dos construcciones del tipo tinha+participio, que se sitúan en subrdinaciones de relativo, tengan interpretación resultativa. En este caso tinhã 
metido expresaría una situación resultativa simultánea a la acción designada por tirou, mientras que tinha feito un estado resultativo simultáneo a metera, así como se propone en (30c).

(30) a. saco a Josep Abarimatia dela prisiõ ẽla qual lo auiã metido por ẽbidia por quãto el auia descẽdido dela cruz el cuerpo de Jesu Christo e lo auia metido enel monumẽto quel auia fecho para si (Sevilla, KL 6462-6468).

b. tirou a Josep Abaramatia da presam: na qual o tinhã metido por ẽueja, por quanto elle deçera da cruz o corpo de Jhesu Christo e o metera no moymento que tinha feito pera sy (Lisboa, KL 4742-4746).

c. sacó a José de Arimatea de la prisión en la cual lo tenían metido por envidia por cuanto él había descendido de la cruz el cuerpo de Jesucristo y lo había metido en el monumento que él tenía hecho para sí mismo

Campos (2005: 134), uniendo la cuestión de las alternancias del tipo mandou tem mandado y mandara tinha mandado, respectivamente, considera que las formas simples tienen función de aoristo, mientras que las formas compuestas desempeñan la de perfecto. A nuestro modo de ver, sin embargo, en nuestros ejemplos la oposición parece darse entre formas simples perfectivas y construcciones resultativas. Sobre la base de lo arriba expuesto, las cinco construcciones portuguesas del tipo teer+participio presentadas en (27-30) -teẽs negado, tẽ feita, tinha segurado, tinhã metido, tinha feito- pueden ser excluidas de entre los tiempos verbales compuestos, puesto que parecen constituir construcciones resultativas en el texto portugués. Si esto es cierto, el número de las construcciones susceptibles de tiempos compuestos será inferior al que ha sido establecido después de la recogida de datos, y los once casos de aver serán contrastados conde con diecinueve casos de teer. En conscuencia, en la versión portuguesa la proporción de aver+participio puede tener una representación más sólida a la habitual de la época, lo que podemos atribuir a la influencia del original en español. 


\section{Conclusiones}

En las páginas precedentes hemos contrastado el uso y la configuración de los tiempos verbales compuestos en la edición española de SeviIla y la portuguesa de Lisboa de la Historia de Vespasiano con el objetivo de si en esta se pueden detectar huellas de influencia española, explicables con un modelo escrito en esta lengua, del que es, según se supone, traducción. El análisis ha demostrado que a las formas de tiempos verbales compuestos de la edición sevillana les corresponde una gran variedad de soluciones en la lisboeta, por lo cual esta se mantiene bastante autónoma respecto a aquella. El examen detallado también ha probado, sin embargo, que no se puede excluir que el texto portugués haya sido influido por un texto fuente escrito en español.

En términos generales, la proporción de aver y teer como auxiliares de tiempos compuestos en la edición portuguesa corresponde a las normas habituales de la época, determinadas por estudios previos, pero descontando algunos casos ambiguos de teer+participio, de intepretación probablemente resultativa, estamos ante una frecuencia mayor de aver, que puede ser manifestación de la influencia de un original escrito en español. El predominio de los casos sin concordancia participial, especialmente en las construcciones formadas con aver, es superior a la habitual, lo que también debe ser atribuido a la influencia española. En cuanto a las soluciones del texto portugués que corresponden a diferentes tiempos verbales de la edición sevillana se debe decir que, además de ser variadas, algunas de ellas parecen incluso sorprendentes y dan la impresión de que el autor-traductor intentaba conscientemente evitar aquellos paralelos formales con el modelo español que no representaban la norma del portugués de la época. Es especialmente notable el alto número de variantes que la versión portuguesa ofrece para expresar anterioridad inmediata en el pasado, donde la edición sevillana contiene formas de pretérito anterior. Se debe suponer, pues, que las construcciones del tipo oue+participio sonarían ya anticuadas en el portugués, y las dos ocurrencias de esta estructura aparecen, probablemente, por influencia del texto fuente en español. 


\section{BIBLIOGRAFÍA}

Andrés Díaz, Ramón de. Gramática comparada de las lenguas ibéricas. Gijón: Ediciones Trea, 2013. Impreso.

Andres-Suárez, Irene. El verbo español. Sistemas medievales y sistema clásico. Madrid: Gredos, 1994. Impreso.

Baranda, Nieves. "Compendio bibliográfico sobre la narrativa caballeresca breve." Alicante : Biblioteca Virtual Miguel de Cervantes, 2014. Edición digital a partir de María Eugenia Lacarra (ed.), Evolución narrativa e ideológica de la literatura caballeresca. Bilbao: Universidad del País Vasco, Servicio Editorial, 1991. 183-191. Web. 09.05.2016.

Berta, Tibor. "Os tempos verbais compostos nas versões castelhana e portuguesa da História do Mui Nobre Vespasiano Imperador de Roma". Bartha-Kovács Katalin et al. (eds.). "Transfert nec mergitur”. Albert Sándor 65. születésnapjának tiszteletére. Szeged: JatePress, 2014a. 141-151. Impreso.

Berta, Tibor. "Las construcciones posesivo-resultativas y la eliminación de la concordancia del participio en los tiempos verbales compuestos del portugués". Colindancias. Revista de la Red Regional de Hispanistas de Europa Central, No. 5 (2014b): 217241. Impreso.

Boléo, Manuel de Paiva. O perfeito e o pretérito em português em confronto com as outras línguas românicas: estudo de carácter sintático-estilístico. Coimbra: Universidade de Coimbra, 1937. Impresso.

Brocardo, Maria Teresa. "Portuguese pluperfect: elements for a diachronic approach". Estudos Linguísticos/Linguistic Studies, No. 5 (2010): 117-130. Web. 23.05.2016.

Brocardo, Maria Teresa. "O 'passado do passado' - alguns dados para a história do pretérito mais-que-perfeito em português". Verba hispanica, No. 20/1 (2012): 33-48. Web. 23.05.2016.

Calzado Roldán, Araceli. "La pérdida de concordancia del participio con el objeto en los tiempos compuestos medievales". Interlingüística, No. 6 (1997): 23-26. Web. 23.06.2016.

Campos, Maria Henriqueta Costa. "Para a unificação dos valores do perfeito e do mais-que-perfeito em português". D. Carvalho et al. (eds). Des(a)fiando Discursos. Homenagem a Maria Emília Ricardo Marques. Lisboa: Universidade Aberta, 2005. 133-139. Web. 23.05.2016. 
Cardoso, Adriana y Pereira, Susana. "Contributos para o estudo da emergência do tempo composto em português". Revista da ABRALIN, Vol. 2, No. 2 (2003): 159-181. Web. 31.05.2016.

Carrasco González, Juan M. "Algunos indicadores del portugués clásico en la obra de Bernardim Ribeiro". Estudis Romànics, Vol. 35 (2013): 173-188. Web. 15.05.2016.

Carrasco González, Juan M. "Evolución de los tiempos compuestos en portugués durante los siglos XVI y XVII". Archivum, No. 64 (2014): 77-100. Web. 08.05.2016.

Carrasco González, Juan M. "Influencia del español en la prosa barroca portuguesa: los tiempos compuestos". Revista de Filología Hispánica, Vol. 31, No. 1 (Ene., 2015): 79-96. Web. 08.05.2016.

Costa, Maria João. 'Os verbos 'aver' e 'teer' no português arcaico - breve sinopse". Filologia linguística portuguesa, 12/1 (2010): 59-68. Web. 09.05.2016.

Dias, Epiphanio da Silva. Syntaxe histórica portuguêsa. Lisboa: Sá da Costa Editora, 1959. Impresso.

García de Diego, Vicente. Gramática histórica española. Madrid: Gredos, 1970. Impreso.

Hanssen, Federico. Gramática histórica de la lengua castellana. París: Ediciones Hispano-Americanas, 1966. Impreso.

Harre, Catherine E. Tener + past participle: a case study in linguistic description. London / New York: Routledge. 1991. Print.

Hook, David, and Penny Newman. Estoria do muy nobre Vespesiano Emperador de Roma. Exeter: Exeter University, 1983. Print.

Huber, Joseph. Gramática do português antigo. Lisboa: Fundação Calouste Gulbenkian, 2006. Impresso.

Irmen, Friedrich. "O pretérito composto em português". Revista de Portugal, Série A: Língua Portuguesa, No. 31 (1966): 222-238. Impresso.

Lapesa, Rafael. Historia de la española. Madrid: Gredos, 1988. Impreso.

Lapesa, Rafael. Estudios de morfosintaxis histórica del español. Madrid: Gredos, 2000. Impreso.

Machado, José Barbosa. "Alguns conectores e marcadores de discurso em três versões 'Da História do Mui Nobre Vespasiano Imperador de Roma'". Estudos Linguísticos/Linguistic Studies, No. 2 (2008): 99-122. Web. 09.05.2016.

Machado, José Barbosa (ed.). História do mui Nobre Vespasiano Imperador de Roma. Edição e estudo. Braga: Edições Vercial, 2010. Kindle Version. 
Machado, José Barbosa. "Press and translation as Changing Factors in the 15th century portuguese language and culture". Web. 29.05.2016. http://alfarrabio.di.uminho.pt/vercial/zips/machad13.pdf

Mattos e Silva, Rosa Virgínia. "Observações sobre a variação no uso dos verbos ser, estar, haver, ter no galego-português ducentista". Estudos Linguísticos e Literários, No. 19 (1997): 253-286. Impresso.

Mattos e Silva, Rosa Virgínia. "Vitórias de ter sobre haver nos meados do século XVI: usos e teoria em João de Barros". Rosa Virgínia Mattos e Silva y Américo Venâncio Lopes Machado Filho (org.) O português quinhentista: estudos linguísticos. Salvador: Universidade Federal da Bahia / Universidade Estadual de Feira de Santana, 2002a: 119142. Web. 24.05.2016.

Mattos e Silva, Rosa Virgínia. "A variação ser/estar e haver/ter nas Cartas de D. João III entre 1540 e 1553: comparação com os usos coetâneos de João de Barros". Rosa Virgínia Mattos e Silva y Américo Venâncio Lopes Machado Filho (org.) O português quinhentista: estudos linguísticos. Salvador: Universidade Federal da Bahia / Universidade Estadual de Feira de Santana, 2002b: 143-160. Web. 24.05.2016.

Mattoso Câmara Jr, Joaquim. História e estrutura da língua portuguesa. Rio de Janeiro: Padrão,1975. Impresso.

Mendonça Cohen, Maria Antonieta Amarante de. "Gramaticalização e Reanálise na Língua Portuguesa”. Caligrama, No. 1 (1988): 43-52. Web. 31.05.2016.

Olbertz, Hella. Verbal Periphrases in a Functional Grammar of Spanish. Berlin / New York: Mouton de Gruyter, 1998. Print.

Osório, Paulo. "Linguística histórica e história da língua: aportações teóricas e metodológicas". Web. 08.05.2016.

http://dlcv.fflch.usp.br/sites/dlcv.fflch.usp.br/files/01_1.pdf.

Osório, Paulo. "Os verbos ser, estar, ter e haver no Leal Conselheiro de D. Duarte: achegas para um quadro linguístico do século xv". Studia Romanica Posnaniensia, Vol. 40/1 (2013): 115-132. Web. 15.05.2016.

Penny, Ralph. Gramática histórica del español. Barcelona: Ariel, 2006. Impreso.

Pereira, Francisco Maria Esteves. Introdução à História de Vespasiano Imperador de Roma. Lisboa: Typ. da Livraria Ferin, 1905. Impresso.

Pountain, Christopher J. "Copulas, Verbs of Possession and Auxiliaries in Old Spanish: The Evidence for Structurally Interdependent Changes". Bulletin of Hispanic Studies, Vol. 62, No. (1985): 337-355. Print. 
Rodríguez Molina, Javier. "Algunas reflexiones sobre el origen y formación de la perífrasis haber + participio en la lengua medieval". Res Diachronicae, No. 2 (2003): 294-302. Web. 23.05.2016.

Romani, Patricia. "Tiempos de formación romance I. Los tiempos compuestos". Concepción Company Company (ed.). Sintaxis histórica de la lengua española. Primera parte: La frase verbal. México D. F.: Universidad Nacional Autónoma de México / Fondo de Cultura Económica, 2006. 243-346. Impreso.

Said Ali, Manuel. Gramática histórica da língua portuguesa. São Paulo: Melhoramentos, 1964. Impresso.

Yllera, Alicia. Sintaxis histórica del verbo español: las perífrasis verbales. Zaragoza: Pórtico, 1980. Impreso.

Vázquez Cuesta, Pilar y Mendes da Luz, Maria Albertina. Gramática portuguesa. Madrid: Gredos, 1987. Impreso.

\title{
Tibor Berta
}

\section{THE SPANISH INFLUENCE IN THE PORTUGUESE VERSION OF THE HISTORY OF VESPASIAN. THE COMPOUND TENSES}

\begin{abstract}
Summary
Several researchers have called attention to the great number of Spanish vocabulary elements that appear in the Portuguese version of the medieval History of Vespasian. It narrates the destruction of Jerusalem by the Roman emperor and it was published in Lisbon in 1496 by Valentino Morávia. The presence of this vocabulary proves that the Portuguese text was translated from Spanish. Based on this assumption, in this paper we will examine, through a contrastive analysis of examples gathered from the text edited in Lisbon and the one in Seville, almost identical in content, if this influence can also be detected at the level of grammar, especially in the field of compound tenses of transitive verbs.

Keywords: historical morphosyntax of the Spanish language, historical morphosyntax of the Portuguese language, Ibero-Romance linguistics, compound tenses, Spanish influence in Portuguese.
\end{abstract}

128 